\title{
Multifocal pattern dystrophy simulating fundus flavimaculatus
}

INSERM

\section{Source}

INSERM. (1999). Orphanet: an online rare disease and orphan drug data base. Multifocal pattern dystrophy simulating fundus flavimaculatus. ORPHA:99003

Multifocal pattern dystrophy simulating fundus flavimaculatus is a patterned dystrophy of the retinal pigment epithelium (see this term) characterized by multiple yellowish irregular flecks scattered or interconnected around the macula, simulating what is observed in Stargardt disease (see this term), and usually asymptomatic until adulthood when patients present with a slowly progressive loss of vision that often only becomes apparent in old age. 